\title{
Birth outcomes following cesarean delivery on maternal request: a population-based cohort study
}

Yanfang Guo PhD, Malia S.Q. Murphy PhD, Erica Erwin MSc, Romina Fakhraei MSc, Daniel J. Corsi PhD, Ruth Rennicks White BScN, Alysha L.J. Harvey MSc, Laura M. Gaudet MD, Mark C. Walker MD, Shi Wu Wen PhD, Darine El-Chaâr MD

Cite as: CMAJ 2021 May 3;193:E633-44. doi: 10.1503/cmaj.202262

\begin{abstract}
BACKGROUND: Data on the effect of cesarean delivery on maternal request (CDMR) on maternal and neonatal outcomes are inconsistent and often limited by inadequate case definitions and other methodological issues. Our objective was to evaluate the trends, determinants and outcomes of CDMR using an intent-to-treat approach.
\end{abstract}

METHODS: We designed a populationbased retrospective cohort study using data on low-risk pregnancies in Ontario, Canada (April 2012-March 2018). We assessed temporal trends and determinants of CDMR. We estimated the relative risks for component and composite outcomes used in the Adverse Outcome Index (AOI) related to planned CDMR compared with planned vaginal delivery using generalized estimating equation models. We compared the Weighted Adverse Outcome Score (WAOS) and the Severity Index (SI) across planned modes of delivery using analysis of variance.

RESULTS: Of 422210 women, $0.4 \%$ ( $n=1827$ ) had a planned CDMR and 99.6\% ( $n=420383$ ) had a planned vaginal delivery. The prevalence of CDMR remained stable over time at $3.9 \%$ of all cesarean deliveries. Factors associated with CDMR included late maternal age, higher education, conception via in vitro fertilization, anxiety, nulliparity, being White, delivery at a hospital providing higher levels of maternal care and obstetrician-based antenatal care. Women who planned CDMR had a lower risk of adverse outcomes than women who planned vaginal delivery (adjusted relative risk $0.42,95 \%$ confidence interval $[\mathrm{Cl}] 0.33$ to 0.53$)$. The WAOS was lower for planned CDMR than planned vaginal delivery (mean difference $-1.28,95 \% \mathrm{Cl}$ -2.02 to -0.55$)$. The SI was not statistically different between groups (mean difference $3.6,95 \% \mathrm{Cl}-7.4$ to 14.5 ).

Interpretation: Rates of CDMR have not increased in Ontario. Planned CDMR is associated with a decreased risk of short-term adverse outcomes compared with planned vaginal delivery. Investigation into the long-term implications of CDMR is warranted. esarean delivery is the most common inpatient surgical procedure in North America, ${ }^{1,2}$ where rates often exceed World Health Organization recommendations (10\%-15\% of deliveries). ${ }^{3}$ Given the financial and resource implications of cesarean deliveries on health care systems, the contribution of cesarean deliveries on maternal request (CDMR) to rising cesarean section rates is of ongoing interest. Women may prefer CDMR for many reasons, including scheduling convenience, anxiety regarding labour pain, perceptions that the quality of obstetrical care is better for women who have cesarean deliveries, and concerns about possible urinary incontinence and sexual dysfunction after vaginal delivery. ${ }^{4-7}$ Challenges in characterizing the epidemiology of CDMR include the lack of internationally accepted case definitions and inconsistencies in documentation that hinder meaningful comparisons across jurisdictions. ${ }^{8-11}$ In Canada, the prevalence of CDMR has been estimated at $2 \%$ of cesarean deliveries, ${ }^{12}$ but robust contemporary data are lacking.

The benefits of vaginal delivery are well known and include a lower risk of transient tachypnea of the newborn, newborn exposure to the vaginal microbiome, shorter maternal hospital stays and lower risk of complications associated 
with abdominal surgeries. The findings of 1 Canadian study suggest that midpelvic operative vaginal delivery is associated with a greater risk of severe birth and obstetric trauma than cesarean delivery. ${ }^{13}$ Evidence on the risks and benefits of CDMR is sparse, and existing data are inconsistent. ${ }^{14-19}$ Analyses are frequently limited by inadequate case definitions and unaddressed confounding from baseline maternal and neonatal factors. ${ }^{4,11}$ Professional organizations in the United States, Canada and Europe do not recommend CDMR over vaginal delivery. ${ }^{11,20-22}$ Patient counselling is suggested to inform patients of pain management options, and of potential benefits and harms related to cesarean deliveries. However, obstetrical care providers often accede to patient preferences, given the ethical imperative of patient autonomy. ${ }^{23-27}$ Contemporary, high-quality observational studies leveraging robust population-based data are required. Our objective was to evaluate the trends, determinants and outcomes of CDMR compared with planned vaginal delivery using an intent-to-treat approach.

\section{Methods}

\section{Study design and population}

We conducted a population-based retrospective cohort study of low-risk pregnancies resulting in a live birth or intrapartum stillbirth ( $\geq 500 \mathrm{~g}$ ) whose deliveries occurred in an Ontario, Canada, hospital from Apr. 1, 2012, to Mar. 31, 2018. We identified low-risk pregnancies using the definition provided by Health Quality Ontario, which is based on pregnancies graded as Robson class criteria 1 to $4 .{ }^{28,29}$ Briefly, this included singleton pregnancies with cephalic presentation that were delivered at term (between $\geq 37$ weeks' and $\leq 42$ weeks' gestation). We excluded pregnancies with medical or prelabour indications for cesarean delivery, as well as records with missing data or data quality issues. The specific variables used to define medical or prelabour indications for cesarean delivery are detailed in Appendix 1, available at www.cmaj.ca/lookup/ doi/10.1503/cmaj.202262/tab-related-content. We further excluded mothers with a cesarean delivery in a previous pregnancy.

\section{Data sources}

We obtained data from the Better Outcomes Registry \& Network (BORN) Ontario, which captures maternal and neonatal information and outcome data for all Ontario births. ${ }^{30}$ Data quality assessments show good agreement of BORN variables with patient records, including for the variable "indications for cesarean section" ( $\kappa 0.92,95 \%$ confidence interval $[\mathrm{Cl}] 0.89$ to 0.95$).{ }^{31}$ To improve outcome ascertainment, we linked records with maternal obstetrical discharge abstracts, and with stillbirth and newborn abstracts from the Canadian Institute for Health Information Discharge Abstract Database.

\section{Exposures}

We used an intent-to-treat methodology to distinguish planned CDMR and planned vaginal delivery subgroups (Figure 1). ${ }^{11}$ The intent-to-treat design addresses a frequently cited challenge in distinguishing the potential risks and benefits of CDMR. ${ }^{11,22}$ Limitations of alternative approaches (i.e., using insufficient proxies for (DMR) include misguided estimates of harm or benefit when unplanned cesarean deliveries are unaccounted for or the impact of labour on maternal and neonatal outcomes cannot be addressed. We defined CDMR in keeping with guidance provided by the American College of Obstetricians and Gynecologists ${ }^{22}$ and the Society for Obstetricians and Gynaecologists of Canada. ${ }^{32}$ The BORN database routinely captures information on the type (i.e., "planned - as scheduled," "planned - not as scheduled," "unplanned") and indications for cesarean deliveries, including whether or not it was by maternal request. Therefore, we further limited CDMR cases to those that were planned, and where records showed that cesarean delivery was by maternal request. We included unplanned cesarean deliveries in the planned vaginal delivery group because women originally intended to deliver vaginally.

\section{Outcomes}

The primary outcome was the Adverse Outcome Index (AOI), a composite of 10 adverse events related to labour and delivery. ${ }^{33,34}$ The $\mathrm{AOI}$ is reported as the percentage of individual patients with at least 1 adverse event relative to the total number of deliveries. As the AOI may be influenced by dominant outcomes, it cannot be used as an exclusive measure of quality and safety. For this reason, we also measured the Weighted Adverse Outcomes Score (WAOS) and the Severity Index (SI). The WAOS reflects a combination of the frequency and severity of events, and the SI evaluates the severity of adverse events among the pregnancies with an adverse event. For the WAOS, each AOI component is assigned a weighted score, and the WAOS represents the sum of all scored events, divided by the total number of deliveries. The $\mathrm{SI}$ is calculated by dividing the WAOS by the number of deliveries with an adverse event. These perinatal health indicators have been previously used in research using populationbased perinatal databases. ${ }^{35}$ The elements and calculations for the AOI, WAOS and SI are provided in Appendix 2, and the specific variables and codes we used to define each component outcome of the AOI are detailed in Appendix 3, both available at www.cmaj.ca/lookup/doi/10.1503/cmaj.202262/ tab-related-content.

\section{Covariates}

We identified potential covariates and confounders based on a literature review, review of a directed acyclic graph (DAG), as well as data availability. Covariates included maternal age, neighbourhood-level income and education, race, parity, prepregnancy body mass index (BMI), gestational weight gain, method of conception, drug use, alcohol use, smoking during pregnancy, prenatal class attendance, self-reported anxiety and depression, antenatal health care provider, maternity hospital level-of-care, ${ }^{36}$ gestational age, infant sex and birth weight. 


\section{Statistical analysis}

We used summary statistics and standardized mean differences to compare maternal, obstetrical and delivery characteristics between planned CDMR and planned vaginal delivery groups. We evaluated the contribution of CDMR to the cesarean delivery rate in Ontario over the study period with a Cochran-Armitage trend test. We employed a multivariable logistic regression model to generate adjusted odds ratios (ORs) and $95 \% \mathrm{Cls}$ to estimate the strength of association between covariates and planned CDMR. To evaluate the association of planned mode of delivery with adverse outcomes, we estimated crude and adjusted relative risks (RRs) with $95 \% \mathrm{Cl}$ using generalized estimating equation models with a log-link function and a Poisson distribution with a robust error variance. ${ }^{37}$ We used multiple imputation methods to account for the missing data of covariates and confounders in the regression models. Five complete data sets were imputed by using the fully conditional specification method (detailed in Appendix 4, available at www.cmaj.ca/lookup/doi/10.1503/cmaj.202262/ tab-related-content).

We identified group differences in WAOS and SI by ANOVA, and used Dunnett's correction, where appropriate, to control the family-wise error rate. We used the tableone package of $\mathrm{R}$ to produce the study characteristics table by exposure group. We used SAS version 9.4 (SAS Institute) to perform all other analyses. We used 2-tailed tests of statistical significance with a threshold of $p<0.05$.

\section{Sensitivity analysis}

We conducted sensitivity analyses to assess the impact of our analytical strategies on the findings. Specifically, we used generalized estimating equation models to estimate crude and adjusted RRs with $95 \% \mathrm{Cls}$ for the AOI with revisions to our study cohort and comparison groups. First, we limited our cohort to nulliparous women to determine whether or not parity had a modifying effect on adverse outcomes. We did another analysis in which we separated unplanned cesarean deliveries from the planned vaginal delivery group to assess the extent to which unplanned cesarean deliveries contributed to the risk of adverse outcomes in the vaginal delivery group. Next, we assessed study outcomes among women with planned cesarean deliveries for medical indications who otherwise met the study inclusion criteria. These women were excluded from the main analysis. For our final sensitivity analysis, we limited the study cohort to include only records with complete data before

All pregnancies that resulted in delivery of a full-term

cephalic, singleton live birth or intrapartum stillbirth weighing

$\geq 500 \mathrm{~g}$ in Ontario, Canada from Apr. 1, 2012, to Mar. 31, 2018 $n=700317$

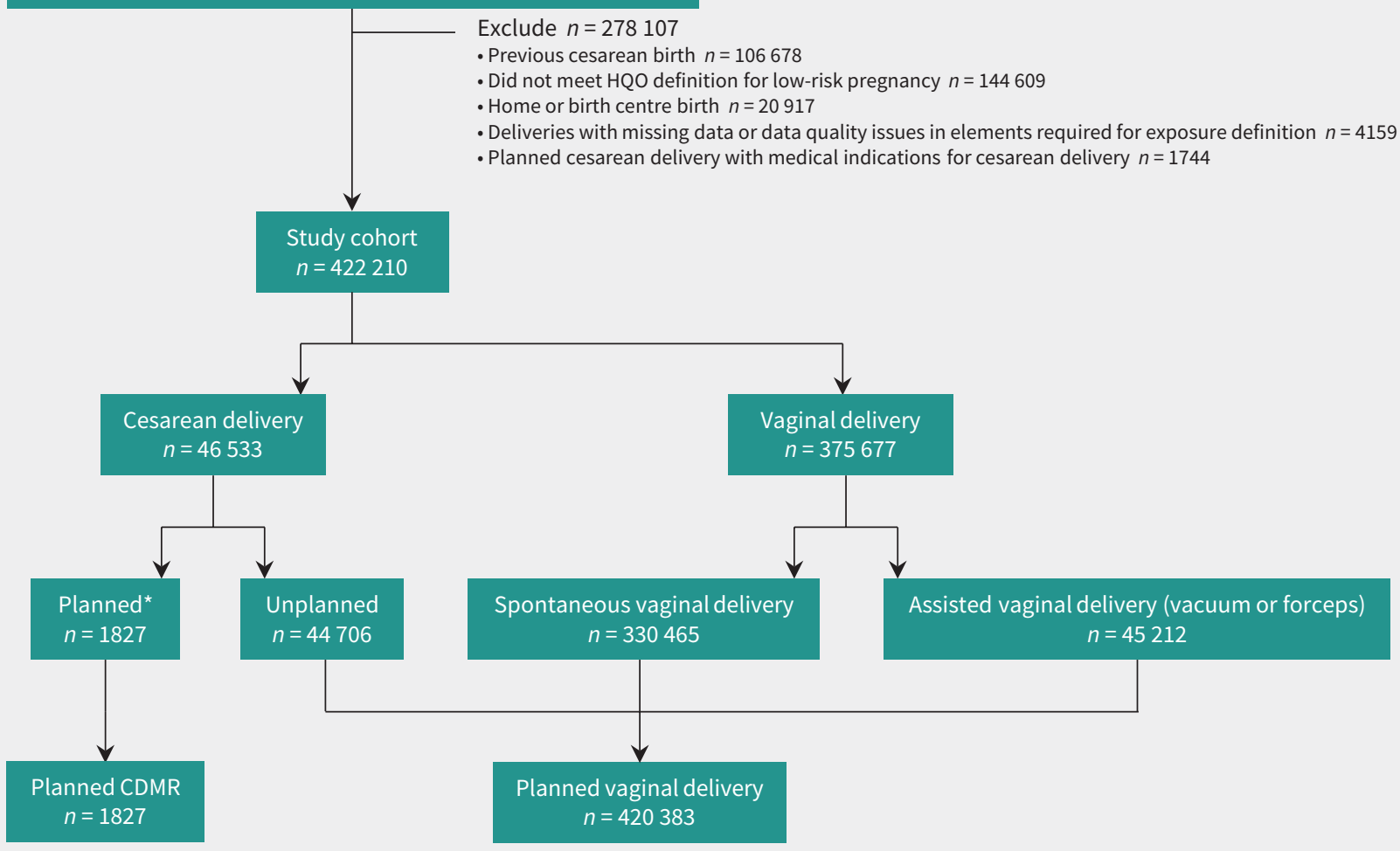

Figure 1: Flow chart of cohort development. All deliveries were identified through Better Outcomes Registry \& Network Ontario. Note: CDMR = cesarean delivery on maternal request, $\mathrm{HQO}=$ Health Quality Ontario. ${ }^{*}$ Planned cesarean deliveries included $83.8 \%(n=1531)$ that were planned (as scheduled), $13.5 \%(n=247)$ that were planned (not as scheduled) and 2.6\% $(n=49)$ that were planned with no specification regarding scheduling. 
multiple imputation (i.e., complete case analysis). This sensitivity analysis was designed to test the performance of our multiple imputation approach. We excluded records that had missing data on any covariates included in the adjusted RR models.

\section{Ethics approval}

This study was reviewed and approved by the Ottawa Health Science Network Research Ethics Board (20180440-01H;20180558-01H).

Table 1 (part 1 of 2): Characteristics of women with low-risk singleton pregnancies resulting in a live or intrapartum stillbirth delivery in Ontario, Canada, between 2012 and 2018, by planned mode of delivery

\begin{tabular}{|c|c|c|c|c|}
\hline Characteristics & $\begin{array}{c}\text { No. }(\%) \text { of } \\
\text { pregnancies* } \\
n=422210\end{array}$ & $\begin{array}{c}\text { No. (\%) of planned } \\
\text { CDMR* }^{\star} \\
n=1827\end{array}$ & $\begin{array}{l}\text { No. }(\%) \text { of planned } \\
\text { vaginal delivery* } \\
\quad n=420383\end{array}$ & SMD \\
\hline Maternal age, $y r$, mean \pm SD & $29.7 \pm 5.2$ & $32.5 \pm 5.7$ & $29.7 \pm 5.2$ & 0.5 \\
\hline \multicolumn{5}{|l|}{ Neighbourhood family income quintile } \\
\hline Quintile 1 (lowest) & $92362(21.9)$ & $365(20.0)$ & $91997(21.9)$ & 0.2 \\
\hline Quintile 2 & $76406(18.1)$ & $288(15.8)$ & $76118(18.1)$ & \\
\hline Quintile 3 & $80216(19.0)$ & $307(16.8)$ & $79909(19.0)$ & \\
\hline Quintile 4 & $91771(21.7)$ & $414(22.7)$ & $91357(21.7)$ & \\
\hline Quintile 5 (highest) & $57372(13.6)$ & $332(18.2)$ & $57040(13.6)$ & \\
\hline Missing & $24083(5.7)$ & $121(6.6)$ & $23962(5.7)$ & \\
\hline \multicolumn{5}{|l|}{ Neighbourhood education level quintile $†$} \\
\hline Quintile 1 (lowest) & $82632(19.6)$ & $246(13.5)$ & $82386(19.6)$ & 0.3 \\
\hline Quintile 2 & $88891(21.1)$ & $306(16.7)$ & $88585(21.1)$ & \\
\hline Quintile 3 & $84780(20.1)$ & $294(16.1)$ & $84486(20.1)$ & \\
\hline Quintile 4 & $86618(20.5)$ & $423(23.2)$ & $86195(20.5)$ & \\
\hline Quintile 5 (highest) & $58489(13.9)$ & $449(24.6)$ & $58040(13.8)$ & \\
\hline Missing & $20800(4.9)$ & $109(6.0)$ & $20691(4.9)$ & \\
\hline \multicolumn{5}{|l|}{ Maternal race } \\
\hline White & $166531(39.4)$ & $886(48.5)$ & $165645(39.4)$ & 0.2 \\
\hline Asian & $67274(15.9)$ & $263(14.4)$ & $67011(15.9)$ & \\
\hline Black & 16639 (3.9) & $44(2.4)$ & 16595 (3.9) & \\
\hline Other & 15208 (3.6) & $76(4.2)$ & 15132 (3.6) & \\
\hline Missing & $156558(37.1)$ & $558(30.5)$ & $156000(37.1)$ & \\
\hline Nulliparous & 203406 (48.2) & $1140(62.4)$ & $22266(48.1)$ & 0.3 \\
\hline Prepregnancy BMI, kg/m², median (IQR) & $23.4(20.9-27.2)$ & $23.2(20.7-27.0)$ & $23.4(20.9-27.2)$ & 0.05 \\
\hline \multicolumn{5}{|l|}{ Gestational weight gain $\ddagger$} \\
\hline Less than recommended & $100444(23.8)$ & $336(18.4)$ & $100108(23.8)$ & 0.2 \\
\hline Within recommended range & $81936(19.4)$ & $333(18.2)$ & $81603(19.4)$ & \\
\hline More than recommended & $199721(47.3)$ & $929(50.8)$ & $198792(47.3)$ & \\
\hline Missing & 40109 (9.5) & $229(12.5)$ & 39880 (9.5) & \\
\hline \multicolumn{5}{|l|}{ Conception type } \\
\hline In vitro fertilization & $5484(1.3)$ & $122(6.7)$ & $5362(1.3)$ & 0.3 \\
\hline Intrauterine insemination and other ART & $5678(1.3)$ & $38(2.1)$ & $5640(1.3)$ & \\
\hline Spontaneous & $404200(95.7)$ & $1645(90)$ & $402555(95.8)$ & \\
\hline Missing & $6848(1.6)$ & $22(1.2)$ & $6826(1.6)$ & \\
\hline Maternal drug use during pregnancy§ & $8601(2.0)$ & $31(1.7)$ & $8570(2.0)$ & 0.05 \\
\hline Maternal alcohol use during pregnancy§ & $9637(2.3)$ & $56(3.1)$ & $9581(2.3)$ & 0.05 \\
\hline Maternal smoking§® & $43374(10.3)$ & $154(8.4)$ & $43220(10.3)$ & 0.06 \\
\hline Maternal anxiety§ $\S^{\star \star}$ & $34571(8.2)$ & $257(14.1)$ & $34314(8.2)$ & 0.2 \\
\hline Maternal depression $\S^{\star \star}$ & $30676(7.3)$ & $151(8.3)$ & $30525(7.3)$ & 0.04 \\
\hline
\end{tabular}


Table 1 (part 2 of 2): Characteristics of women with low-risk singleton pregnancies resulting in a live or intrapartum stillbirth delivery in Ontario, Canada, between 2012 and 2018, by planned mode of delivery

\begin{tabular}{|c|c|c|c|c|}
\hline Characteristics & $\begin{array}{c}\text { No. }(\%) \text { of } \\
\text { pregnancies }^{\star} \\
n=422210\end{array}$ & $\begin{array}{c}\text { No. (\%) of planned } \\
\text { CDMR* }^{\star} \\
n=1827\end{array}$ & $\begin{array}{l}\text { No. }(\%) \text { of planned } \\
\text { vaginal delivery* } \\
\quad n=420383\end{array}$ & SMD \\
\hline \multicolumn{5}{|l|}{ Labour type } \\
\hline Spontaneous & $321253(76.1)$ & $154(8.4)$ & 321099 (76.4) & \multirow[t]{4}{*}{4.6} \\
\hline Induced & $97603(23.1)$ & $0(0.0)$ & $97603(23.2)$ & \\
\hline No labour & $3322(0.8)$ & $1673(91.6)$ & $1649(0.4)$ & \\
\hline Missing & $32(0.0)$ & $0(0.0)$ & $32(0.0)$ & \\
\hline \multicolumn{5}{|l|}{ Antenatal health care providert† } \\
\hline Family physician only & $54849(13.0)$ & $60(3.3)$ & $54789(13.0)$ & \multirow[t]{7}{*}{0.6} \\
\hline Obstetrician only & $233439(55.3)$ & $1445(79.1)$ & $231994(55.2)$ & \\
\hline Family physician and obstetrician & $58909(14.0)$ & $234(12.8)$ & $58675(14.0)$ & \\
\hline Midwife & $64429(15.3)$ & $61(3.3)$ & $64368(15.3)$ & \\
\hline None & S & S & $1530(0.4)$ & \\
\hline Other & $6694(1.6)$ & $19(1.0)$ & $6675(1.6)$ & \\
\hline Missing & S & $\mathrm{S}$ & $2352(0.6)$ & \\
\hline \multicolumn{5}{|l|}{ Maternity hospital level of care $\ddagger$} \\
\hline Maternal Level I & $56385(13.4)$ & $134(7.3)$ & $56251(13.4)$ & \multirow[t]{6}{*}{0.4} \\
\hline Maternal Level Ila & $47765(11.3)$ & $134(7.3)$ & $47631(11.3)$ & \\
\hline Maternal Level IIb & $133875(31.7)$ & $431(23.6)$ & $133444(31.7)$ & \\
\hline Maternal Level Ilc & $108030(25.6)$ & $629(34.4)$ & $107401(25.5)$ & \\
\hline Maternal Level III & $76099(18.0)$ & $499(27.3)$ & $75600(18.0)$ & \\
\hline Missing & $56(0.0)$ & $0(0.0)$ & $56(0.0)$ & \\
\hline Infant sex, male & $215860(51.1)$ & $943(51.6)$ & $214917(51.1)$ & 0.04 \\
\hline Infant birth weight, $g$, mean \pm SD & $3462.3 \pm 448.3$ & $3430.2 \pm 427.1$ & $3462.5 \pm 448.4$ & 0.07 \\
\hline Gestational age, wk, median (IQR) & $39.9(39.1-40.7)$ & $39.0(38.7-39.4)$ & $39.9(39.1-40.7)$ & 0.8 \\
\hline \multicolumn{5}{|c|}{ 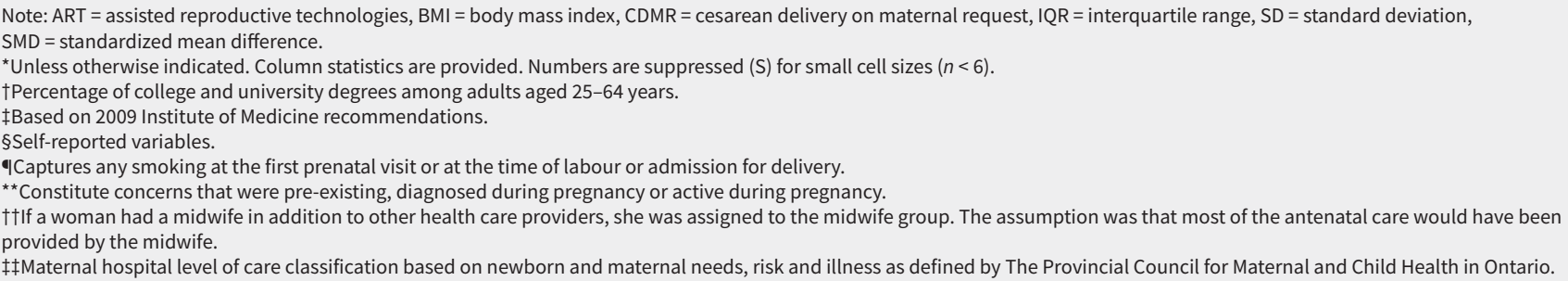 } \\
\hline
\end{tabular}

\section{Results}

A total of 422210 pregnancies met our inclusion criteria, of which $1827(0.4 \%)$ and 420383 (99.6\%) were categorized as planned CDMR and planned vaginal delivery (including unplanned cesarean deliveries), respectively (Table 1).

Our cohort included 46533 cesarean deliveries, of which 1827 (3.9\%) were planned CDMR, and 44706 (96.1\%) were unplanned cesarean deliveries. The proportion of all deliveries that were planned CDMR was $0.5 \%$ in the first and last fiscal years of our study (2012/13 and 2017/18) and the proportion remained stable across all fiscal years $(p=0.3)$.

Planned CDMR was associated with late maternal age ( $\geq 35 \mathrm{yr}$ ), being White, living in a neighbourhood of a higher educational quintiles, gaining more than the recommended weight in pregnancy, nulliparity, conception by in vitro fertilization, anxiety, not attending prenatal classes, delivering at a hospital that provides maternal level IIC or III care and receiving antenatal care from obstetricians (Table 2).

\section{Adverse outcomes and CDMR}

Overall, the AOI was lower in women with planned CDMR $(3.8 \%)$ than those with planned vaginal deliveries (8.3\%) (Table 3). The frequencies of adverse maternal and neonatal outcomes were both lower for women with planned CDMR than those with planned vaginal deliveries. The most common maternal adverse outcomes were unanticipated operative procedures $(1.2 \%, n=21)$ for women who planned 
Table 2 (part 1 of 2): Factors associated with planned CDMR in Ontario, Canada,

between 2012 and 2018*

\begin{tabular}{|c|c|c|c|}
\hline Factor & $\begin{array}{c}\text { No. of } \\
\text { pregnancies* } \\
n=422210\end{array}$ & $\begin{array}{c}\text { No. }(\%) \text { of } \\
\text { planned CDMR } \\
n=1827\end{array}$ & $\begin{array}{c}\text { Adjusted OR } \\
(95 \% \mathrm{Cl}) \dagger\end{array}$ \\
\hline \multicolumn{4}{|l|}{ Maternal age, yr } \\
\hline$<19$ & 12462 & $29(0.23)$ & 0.53 (0.37 to 0.77 ) \\
\hline $20-34$ & 334278 & $1140(0.34)$ & Reference \\
\hline $35-39$ & 63896 & $459(0.72)$ & 2.11 (1.88 to 2.37 ) \\
\hline$\geq 40$ & 11393 & $195(1.71)$ & 4.33 (3.67 to 5.11 ) \\
\hline \multicolumn{4}{|l|}{ Neighbourhood family income quintile } \\
\hline Quintile 1 (lowest) & 92362 & $365(0.40)$ & Reference \\
\hline Quintile 2 & 76406 & $288(0.38)$ & 0.94 (0.79 to 1.10$)$ \\
\hline Quintile 3 & 80216 & $307(0.38)$ & 0.91 (0.78 to 1.06$)$ \\
\hline Quintile 4 & 91771 & $414(0.45)$ & $0.96(0.83$ to 1.11$)$ \\
\hline Quintile 5 (highest) & 57372 & $332(0.58)$ & 0.93 (0.79 to 1.11$)$ \\
\hline \multicolumn{4}{|l|}{ Neighbourhood education level quintilef } \\
\hline Quintile 1 (lowest) & 82632 & $246(0.30)$ & Reference \\
\hline Quintile 2 & 88891 & $306(0.34)$ & 1.06 (0.89 to 1.27 ) \\
\hline Quintile 3 & 84780 & $294(0.35)$ & 1.02 (0.85 to 1.22 ) \\
\hline Quintile 4 & 86618 & $423(0.49)$ & 1.30 (1.10 to 1.54$)$ \\
\hline Quintile 5 (highest) & 58489 & $449(0.77)$ & 1.78 (1.48 to 2.15 ) \\
\hline \multicolumn{4}{|l|}{ Maternal race } \\
\hline White & 166531 & $886(0.53)$ & Reference \\
\hline Non-White & 99121 & $383(0.39)$ & 0.60 (0.53 to 0.68$)$ \\
\hline Missing & 156558 & $558(0.36)$ & 0.87 (0.78 to 0.97$)$ \\
\hline \multicolumn{4}{|l|}{ Parity } \\
\hline 0 & 203406 & $1140(0.56)$ & 2.25 ( 2.02 to 2.50$)$ \\
\hline$\geq 1$ & 218804 & $687(0.31)$ & Reference \\
\hline \multicolumn{4}{|l|}{ Prepregnancy BMI, kg/m² } \\
\hline Underweight $(<18.5)$ & 24499 & $123(0.50)$ & 1.24 (0.99 to 1.57 ) \\
\hline Normal weight (18.5 to 24.9 ) & 211790 & $896(0.42)$ & Reference \\
\hline Overweight (25.0 to 29.9 ) & 89491 & $348(0.39)$ & 0.93 (0.81 to 1.07$)$ \\
\hline Obese $(\geq 30)$ & 56322 & $231(0.41)$ & 1.00 (0.87 to 1.16$)$ \\
\hline \multicolumn{4}{|l|}{ Gestational weight gain§ } \\
\hline Less than recommended & 100444 & $336(0.33)$ & 0.88 (0.75 to 1.04$)$ \\
\hline Within recommended range & 81936 & $333(0.41)$ & Reference \\
\hline More than recommended & 199721 & $929(0.47)$ & 1.18 (1.04 to 1.34$)$ \\
\hline \multicolumn{4}{|l|}{ Conception type } \\
\hline In vitro fertilization & 5484 & $122(2.22)$ & 2.64 (2.15 to 3.24$)$ \\
\hline Intrauterine insemination and other ART & 5678 & $38(0.67)$ & 1.05 (0.75 to 1.45$)$ \\
\hline Spontaneous & 404200 & $1645(0.41)$ & Reference \\
\hline \multicolumn{4}{|l|}{ Maternal anxiety $q^{\star \star}$} \\
\hline No & 387639 & $1570(0.41)$ & Reference \\
\hline Yes & 34571 & $257(0.74)$ & 2.07 (1.79 to 2.40$)$ \\
\hline \multicolumn{4}{|l|}{ Maternal depression $q^{\star \star}$} \\
\hline No & 391534 & $1676(0.43)$ & Reference \\
\hline Yes & 30676 & $151(0.49)$ & 0.97 (0.81 to 1.17$)$ \\
\hline
\end{tabular}


Table 2 (part 2 of 2): Factors associated with planned CDMR in Ontario, Canada,

between 2012 and 2018*

\begin{tabular}{|c|c|c|c|}
\hline Factor & $\begin{array}{c}\text { No. of } \\
\text { pregnancies }^{\star} \\
n=422210\end{array}$ & $\begin{array}{c}\text { No. }(\%) \text { of } \\
\text { planned CDMR } \\
n=1827\end{array}$ & $\begin{array}{c}\text { Adjusted OR } \\
(95 \% \mathrm{CI}) \dagger\end{array}$ \\
\hline \multicolumn{4}{|l|}{ Attended prenatal class } \\
\hline No & 288368 & $1283(0.44)$ & Reference \\
\hline Yes & 101394 & $392(0.39)$ & 0.59 (0.52 to 0.67$)$ \\
\hline \multicolumn{4}{|l|}{ Antenatal health care providert† } \\
\hline Family physician only & 54849 & $60(0.11)$ & 0.21 (0.16 to 0.27$)$ \\
\hline Obstetrician only & 233439 & $1445(0.62)$ & Reference \\
\hline Family physician and obstetrician & 58909 & $234(0.40)$ & 0.72 (0.63 to 0.83 ) \\
\hline Midwife & 64429 & $61(0.09)$ & $0.16(0.13$ to 0.21$)$ \\
\hline None & S & S & S \\
\hline Other & 6694 & $19(0.28)$ & 0.48 (0.30 to 0.76$)$ \\
\hline \multicolumn{4}{|l|}{ Maternal hospital level of care $\ddagger \ddagger$} \\
\hline Level I & 56385 & $134(0.24)$ & Reference \\
\hline Level Ila & 47765 & $134(0.28)$ & $0.86(0.68$ to 1.10$)$ \\
\hline Level IIb & 133875 & $431(0.32)$ & 0.91 (0.75 to 1.12$)$ \\
\hline Level IIc & 108030 & $629(0.58)$ & 1.57 (1.30 to 1.91$)$ \\
\hline Level III & 76099 & $499(0.66)$ & 1.51 (1.24 to 1.85$)$ \\
\hline \multicolumn{4}{|l|}{ Infant sex } \\
\hline Male & 215860 & $943(0.44)$ & Reference \\
\hline Female & 206101 & $884(0.43)$ & 0.97 (0.89 to 1.07 ) \\
\hline \multicolumn{4}{|l|}{ Birth weight, g } \\
\hline$<2500$ & 4259 & $10(0.23)$ & 0.50 (0.27 to 0.93 ) \\
\hline 2500 to 3999 & 368153 & $1643(0.45)$ & Reference \\
\hline$\geq 4000$ & 49782 & $174(0.35)$ & 0.87 (0.74 to 1.02$)$ \\
\hline
\end{tabular}

Note: $\mathrm{ART}$ = assisted reproductive technologies, $\mathrm{BMI}=$ body mass index, $\mathrm{CDMR}=$ cesarean delivery on maternal request, $\mathrm{Cl}=$ confidence interval, $\mathrm{OR}=$ odds ratio.

${ }^{*}$ Counts included in table are identical to Table 1 and are based on data before imputation. Row percentages are presented. Adjusted relative risk estimates were calculated using data imputed using fully conditional specification. Numbers are suppressed (S) for small cell sizes $(n<6)$.

$\dagger$ † multivariate logistic regression model was used to estimate the adjusted odds ratios. The multivariate logistic regression model included maternal age, neighbourhood income level, neighourhood education level, race, parity, BMI, gestational weight gain, method of conception, prenatal class attendance, anxiety, depression, antenatal health care provider, maternal hospital level of care, infant sex and infant birth weight. If one independent variable was treated as the main predictor, the other variables were automatically treated as covariates or confounders. C-statistic $=0.746$.

$\ddagger$ Percentage of college and university degrees among adults 25-64 years old.

$\S$ Based on 2009 Institute of Medicine recommendations.

ISelf-reported variables.

${ }^{\star \star}$ Constitute concerns that were pre-existing, diagnosed during pregnancy or active during pregnancy.

††If a woman had a midwife in addition to other health care providers, she was assigned to the midwife group. The assumption was that most of the antenatal care would have been provided by the midwife.

¥¥Maternal hospital level of care classification based on newborn and maternal needs, risk and illness as defined by The

Provincial Council for Maternal and Child Health in Ontario.

CDMR, and third- or fourth-degree perineal tear $(3.3 \%, n=$ $13686)$ for women who planned vaginal deliveries. Admission or transfer to the neonatal intensive care unit (NICU) was the most common neonatal outcome for both the planned CDMR and planned vaginal delivery groups.

Women who planned CDMR were less likely to have adverse maternal (adjusted RR $0.41,95 \% \mathrm{Cl} 0.30$ to 0.57 ) and neonatal outcomes (adjusted RR $0.42,95 \% \mathrm{Cl} 0.33$ to 0.53 ) than those who planned vaginal deliveries. Accordingly, the risk of any AOI outcome was lower for women who planned CDMR than women who planned vaginal deliveries (adjusted RR $0.42,95 \% \mathrm{Cl} 0.33$ to 0.54 ).

The WAOS was lower in women with planned CDMR than in those with planned vaginal deliveries (mean difference [MD] $-1.28,95 \% \mathrm{Cl}-2.02$ to -0.55 ) (Figure 2), largely because of a lower neonatal WAOS score (MD $-1.35,95 \% \mathrm{Cl}$ -2.00 to -0.69$)$. There was no statistically significant difference in the overall severity of adverse outcomes as measured 
Table 3: Adverse outcomes after planned CDMR and planned vaginal delivery among women with low-risk singleton pregnancies resulting in a live or intrapartum stillbirth delivery in Ontario, Canada, between 2012 and 2018 ( $n=422210)$

\begin{tabular}{|c|c|c|c|c|}
\hline \multirow[b]{2}{*}{ AOI component } & \multirow[b]{2}{*}{$\begin{array}{c}\text { No. }(\%) \text { of } \\
\text { planned CDMR* } \\
n=1827\end{array}$} & \multirow{2}{*}{$\begin{array}{c}\text { No. }(\%) \text { of } \\
\text { planned vaginal } \\
\text { delivery* } \\
n=420383\end{array}$} & \multicolumn{2}{|c|}{$\begin{array}{l}\text { Planned CDMR v. planned vaginal } \\
\text { delivery* }\end{array}$} \\
\hline & & & $\begin{array}{l}\text { Crude RR* } \\
(95 \% \mathrm{Cl})\end{array}$ & $\begin{array}{l}\text { Adjusted RR† } \\
\quad(95 \% \mathrm{CI})\end{array}$ \\
\hline \multicolumn{5}{|l|}{ Maternal component } \\
\hline Maternal death & $0(0.0)$ & $14(0.0)$ & - & - \\
\hline Uterine rupture & $0(0.0)$ & $100(0.0)$ & - & - \\
\hline Maternal intensive care unit admission & S & $446(0.1)$ & S & S \\
\hline Unanticipated operative procedure & $21(1.2)$ & $2212(0.5)$ & 2.18 (1.42 to 3.35$)$ & 2.00 (1.30 to 3.08$)$ \\
\hline Blood transfusion & $19(1.0)$ & $3057(0.7)$ & 1.43 (0.91 to 2.24$)$ & 1.46 (0.93 to 2.30$)$ \\
\hline 3 rd or 4th degree perineal tear & $0(0.0)$ & $13686(3.3)$ & & \\
\hline Any maternal components & $37(2.0)$ & $18336(4.4)$ & $0.46(0.34$ to 0.64$)$ & 0.41 (0.30 to 0.57$)$ \\
\hline \multicolumn{5}{|l|}{ Fetal or neonatal components } \\
\hline $\begin{array}{l}\text { Intrapartum or in-hospital newborn death } \\
\text { with birth weight } \geq 2500 \mathrm{~g} \text {, with no congenital anomalies }\end{array}$ & $0(0.0)$ & $301(0.1)$ & - & - \\
\hline Birth trauma, $\geq 2000 \mathrm{~g}$ & $0(0.0)$ & $2439(0.6)$ & - & - \\
\hline $\begin{array}{l}\text { NICU admission }>2 \mathrm{~d} \text { or transfer within } 24 \mathrm{~h} \\
\text { of birth to a facility with a NICU for an infant } \geq 2500 \mathrm{~g}\end{array}$ & $30(1.6)$ & $12479(3.0)$ & 0.55 (0.39 to 0.79$)$ & 0.52 (0.36 to 0.74$)$ \\
\hline 5-minute Apgar score $<7$ & S & $5353(1.3)$ & S & S \\
\hline Any neonatal component & $34(1.9)$ & $17899(4.3)$ & 0.44 (0.31 to 0.61$)$ & 0.42 ( 0.30 to 0.58$)$ \\
\hline Any AOI component & $70(3.8)$ & $34999(8.3)$ & 0.46 (0.37 to 0.58$)$ & 0.42 (0.33 to 0.54$)$ \\
\hline
\end{tabular}

by the SI between women with planned CDMR and planned vaginal deliveries (MD 3.6, $95 \% \mathrm{Cl}-7.4$ to 14.5 ). However, the severity of maternal outcomes was greater for planned CDMR than planned vaginal deliveries (MD 20.1, 95\% Cl 10.6 to 29.7$)$.

\section{Sensitivity analyses}

Restriction of our cohort to nulliparous women yielded similar results, as did separating unplanned cesarean deliveries from the planned vaginal delivery group and removing cases with missing data. The risk of adverse outcomes among women with planned cesarean deliveries for medical indications was lower than that observed for women with planned vaginal deliveries. The findings of our sensitivity analyses are detailed in Appendix 5, available at www.cmaj.ca/lookup/doi/10.1503/ cmaj.202262/tab-related-content.

\section{Interpretation}

In this population-based study of 422210 deliveries, we showed that rates of planned CDMR in Ontario, Canada, have remained stable at $3.9 \%$ of cesarean deliveries from 2012 to 2018. Factors associated with CDMR included late maternal age, being White, higher education, self-reported anxiety, nulliparity, conception by in vitro fertilization and obstetricianbased antenatal care. In this cohort of low-risk pregnancies, we found that planned CDMR was accompanied by a decreased risk of adverse outcomes. The AOI and WAOS were lower for women with planned CDMR than women with planned vaginal deliveries, and the risk of adverse outcomes was lower after adjusting for confounding factors.

Few others have attempted the intent-to-treat framework to study CDMR, ${ }^{15,19,38}$ and differences in case ascertainment and statistical approaches make it difficult to compare findings across studies. Our findings are similar to those of a retrospective analysis of 66226 nulliparous women in China. Although the authors identified no differences in risk of maternal morbidities between the planned CDMR and vaginal delivery groups, CDMR was associated with neonatal benefits, ${ }^{38}$ including a lower risk of birth trauma, infection, meconium aspiration syndrome and NICU admission. A population-based study from Denmark of low-risk nulliparous women found no differences in the risk for major maternal morbidities between planned CDMR and planned vaginal delivery. ${ }^{15}$ However, the authors noted increases in the risk for anal sphincter tears among women with planned vaginal 


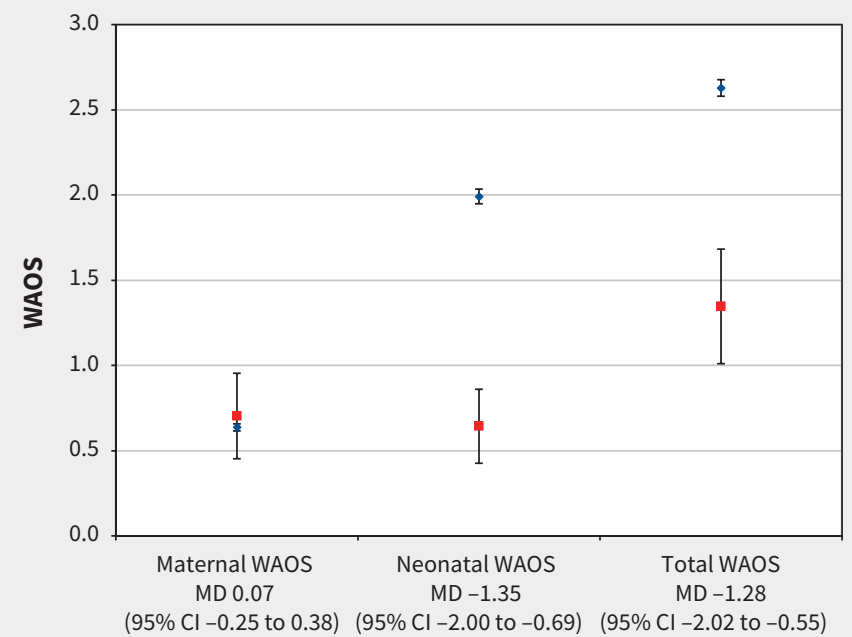

B

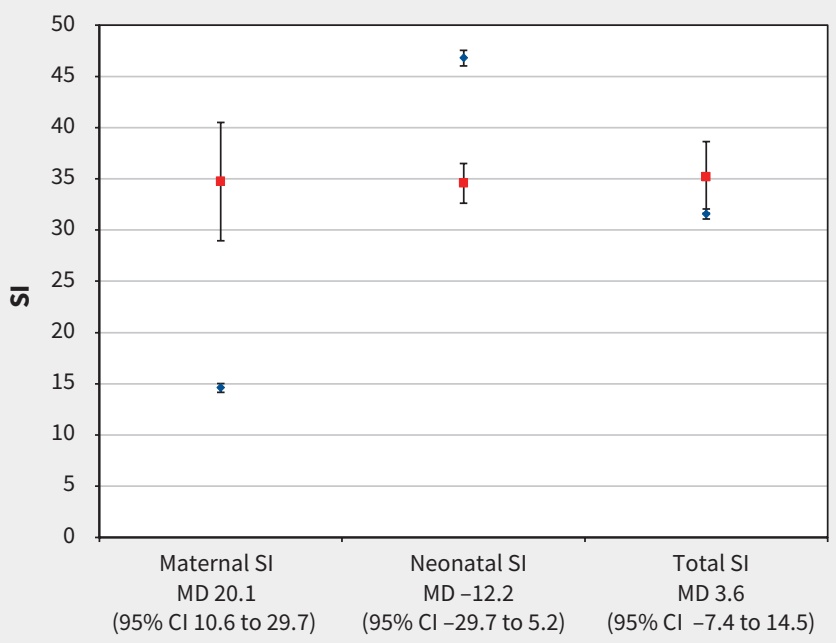

- Planned CDMR Planned vaginal delivery

Figure 2: Weighted Adverse Outcome Scores (WAOS) and Severity Index (SI) scores for adverse outcomes after planned cesarean delivery on maternal request (CDMR) and planned vaginal delivery among women with low-risk singleton pregnancies resulting in a live or intrapartum stillbirth delivery in Ontario, Canada, between 2012 and 2018 ( $n=422$ 210). (A) Maternal component, neonatal component and total WAOS scores; (B) Maternal component, neonatal component and total SI scores. Note: $\mathrm{Cl}=$ confidence interval, $\mathrm{MD}=$ mean difference.

deliveries, and for wound infection among those with planned CDMR, both expected risks associated with these modes of delivery. This is consistent with our findings of a greater frequency of perineal tears for women with planned vaginal deliveries and a greater risk of unanticipated operative procedures for those with planned CDMR, such as cesarean hysterectomy. Unfortunately, there are no published data from randomized controlled trials addressing the impact of CDMR on maternal or neonatal outcomes. Feedback from health care providers and women suggests that such a trial would not be ethically or practically feasible without a patient preference arm. ${ }^{39,40}$

Our finding that CDMR rates have remained stable in Ontario provides reassurance to those concerned about the potential contribution of CDMR to rising cesarean delivery rates. ${ }^{41,42}$ The low prevalence of CDMR in our cohort is consistent with other Canadian reports, ${ }^{12,43}$ but lower than observations from other countries, where estimates of elective cesarean deliveries and CDMR vary from $<10 \%$ in the US ${ }^{8-10}$ to 20\%-50\% in China and Brazil. ${ }^{38,44-46}$ Our findings reaffirm those of others that CDMR is associated with late maternal age and higher socioeconomic status. ${ }^{44,47}$ Primiparity and conception by in vitro fertilization were also determinants of CDMR, suggesting that women with first pregnancies or those who had fertility issues prefer CDMR. The role of care providers in facilitating or influencing a woman's preferred mode of delivery also warrants examination. Although care providers are supportive of a woman's right to choose CDMR, ${ }^{25,26,48}$ surveys show variable willingness to comply with such requests. In our study, care from an obstetrician was a significant determinant of CDMR, suggesting that women who plan CDMR are more likely to seek out care from an obstetrician and that women preferring vaginal deliveries are more likely to seek antenatal care from a midwife.

In addition to the intent-to-treat design, strengths of our study include the use of population-based data, compiling 6 years of provincial data to generate a sample exceeding 750000 births. Further, type (planned v. unplanned) and indications for cesarean deliveries (including maternal request), are variables that are routinely collected at BORN Ontario, making it one of few resources that can reliably be used to investigate CDMR.

\section{Limitations}

As an observational study, we cannot discount potential unmeasured confounders and bias in our data set. Coding errors and lack of acceptance of CDMR in certain facilities may have resulted in misclassification bias. Although we are unable to address reporting bias in our cohort, misclassification of CDMR as cases of cesarean delivery with medical indications would not have affected the findings of our primary analysis. Indeed, the findings of our sensitivity analysis comparing outcomes after cesarean deliveries because of medical or prelabour indications to planned vaginal delivery were not significantly different than our primary analysis. Given the lack of consensus among health care professionals and across 
health care facilities on how to approach CDMR, the potential for misclassification is a challenge that is not unique to our cohort. We also cannot discount bias resulting from the removal of records with missing, ambiguous or discordant case information $(<1 \%)$ and exclusion of home births and deliveries at birth centres $(<3 \%)$. However, the proportion of excluded records was small and the likely impact on our effect estimates is minor. Given the relatively low incidence of CDMR in our population, our sample size for this group was small. We were unable to clarify many pressing questions related to the timing of maternal request, reasons for the request and provider influences on maternal preferences. Finally, the AOI is a standardized performance indicator developed to monitor 10 adverse events occurring during labour and delivery, at the hospital level. ${ }^{34}$ It was not developed to provide measures of safety at the individual patient level. Dominant outcomes may influence the $\mathrm{AOI}$ and we caution readers against interpreting AOI findings independently of the WAOS and SI. Although limitations exist, ${ }^{49,50}$ they are validated measures that provide insight into patient safety.

\section{Conclusion}

This analysis shows that planned CDMR is safe for low-risk pregnancies and may be associated with a lower risk of adverse delivery outcomes compared with planned vaginal deliveries. Although our study addresses concerns related to the immediate implications of planned CDMR, exploration of longer-term risks is needed, including its impact on breastfeeding, ${ }^{51-54}$ and the child's risk for infection and respiratory illness. ${ }^{55-57}$

\section{References}

1. $\mathrm{CIHI}$ Snapshot: Inpatient hospitalizations, surgeries, newborns and childbirth indicators, 2016-2017. Ottawa: Canadian Institute for Health Information (CIHI); 2018. Available: https://secure.cihi.ca/free_products/hospch-hosp -2016-2017-snapshot_en.pdf (accessed 2019 May 23).

2. McDermott KW, Freeman WJ, Elixhauser A. Overview of operating room procedures during inpatient stays in U.S. hospitals, 2014. Statistical Brief No. 233. Rockville (MD): Agency for Healthcare Research and Quality; 2017. Available: www.hcup-us.ahrq.gov/reports/statbriefs/sb233-Operating-Room-Procedures -United-States-2014.jsp (accessed 2019 May 23).

3. Betran AP, Torloni MR, Zhang J, et al. What is the optimal rate of caesarean section at population level? A systematic review of ecologic studies. Reprod Health 2015;12:57.

4. Wiklund I, Andolf E, Lilja H, et al. Indications for cesarean section on maternal request: guidelines for counseling and treatment. Sex Reprod Healthc 2012;3:99-106.

5. Eide KT, Morken N-H, Bærøe K. Maternal reasons for requesting planned cesarean section in Norway: a qualitative study. BMC Pregnancy Childbirth 2019;19:102.

6. Béhague DP, Victora CG, Barros FC. Consumer demand for caesarean sections in Brazil: informed decision making, patient choice, or social inequality? A population based birth cohort study linking ethnographic and epidemiological methods. BMJ 2002;324:942-5.

7. McCourt C, Weaver J, Statham H, et al. Elective cesarean section and decision making: a critical review of the literature. Birth 2007;34:65-79.

8. Gregory KD, Korst LM, Gornbein JA, et al. Using administrative data to identify indications for elective primary cesarean delivery. Health Serv Res 2002;37:1387-401.

9. Gossman GL, Joesch JM, Tanfer K. Trends in maternal request cesarean delivery from 1991 to 2004. Obstet Gynecol 2006;108:1506-16.
10. MacDorman MF, Menacker F, Declercq E. Cesarean birth in the United States: epidemiology, trends, and outcomes. Clin Perinatol 2008;35:293-307.

11. NIH State of the Science Conference: cesarean delivery on maternal request. NIH Consens State Sci Statements 2006;23:1-29.

12. Hanley GE, Janssen PA, Greyson D. Regional variation in the cesarean delivery and assisted vaginal delivery rates. Obstet Gynecol 2010;115:1201-8.

13. Muraca GM, Sabr Y, Lisonkova S, et al. Perinatal and maternal morbidity and mortality after attempted operative vaginal delivery at midpelvic station. CMAJ 2017;189:E764-72.

14. Wax JR. Maternal request cesarean versus planned spontaneous vaginal delivery: maternal morbidity and short term outcomes. Semin Perinatol 2006;30:247-52.

15. Otkjaer AM, Jørgensen HL, Clausen TD, et al. Maternal short-term complications after planned cesarean delivery without medical indication: a registrybased study. Acta Obstet Gynecol Scand 2019;98:905-12.

16. Souza JP, Gülmezoglu AM, Lumbiganon P, et al.; WHO Global Survey on Maternal and Perinatal Health Research Group. Caesarean section without medical indications is associated with an increased risk of adverse short-term maternal outcomes: the 2004-2008 WHO Global Survey on Maternal and Perinatal Health. BMC Med 2010;8:71.

17. Bodner K, Wierrani F, Grünberger W, et al. Influence of the mode of delivery on maternal and neonatal outcomes: a comparison between elective cesarean section and planned vaginal delivery in a low-risk obstetric population. Arch Gynecol Obstet 2011;283:1193-8.

18. Dahlgren LS, von Dadelszen P, Christilaw J, et al. Caesarean section on maternal request: risks and benefits in healthy nulliparous women and their infants. J Obstet Gynaecol Can 2009;31:808-17.

19. MacDorman MF, Declercq E, Menacker F, et al. Neonatal mortality for primary cesarean and vaginal births to low-risk women: application of an "intentionto-treat" model. Birth 2008;35:3-8.

20. Halpern S. SOGC joint policy statement on normal childbirth. J Obstet Gynaecol Can 2009;31:602.

21. The FIGO Committee for the Ethical Aspects of Human Reproduction and Women's Health. Ethical issues in obsetrics and gynecology. London (UK): FIGO House; 2015. Available: http://figo.org/sites/default/files/uploads/wgpublications/ethics/ FIGO\%20Ethical\%20Issues\%202015.pdf4893.pdf (accessed 2019 May 23).

22. ACOG Committee Opinion No. 761: cesarean delivery on maternal request. Obstet Gynecol 2019;133:e73-7.

23. D'Souza R, Arulkumaran S. To 'C' or not to 'C'? Caesarean delivery upon maternal request: a review of facts, figures and guidelines. J Perinat Med 2013;41:5-15.

24. Ecker J. Elective cesarean delivery on maternal request. JAMA 2013;309:1930-6.

25. Rivo JC, Amyx M, Pingray V, et al. Feasibility of 'Mode of Delivery Trial' Study Group. Obstetrical providers' preferred mode of delivery and attitude towards non-medically indicated caesarean sections: a cross-sectional study. BJOG 2018;125:1294-302.

26. Bettes BA, Coleman VH, Zinberg S, et al. Cesarean delivery on maternal request: obstetrician-gynecologists' knowledge, perception, and practice patterns. Obstet Gynecol 2007;109:57-66.

27. Habiba M, Kaminski M, Da Frè M, et al. Caesarean section on request: a comparison of obstetricians' attitudes in eight European countries. BJOG 2006;113:647-56.

28. Robson MS. Classification of caesarean sections. Fetal Matern Med Rev 2001;12:23-39.

29. Health Quality Ontario. Caesarean section deliveries among low-risk women. Toronto: Queen's Printer for Ontario; 2018. Available: http://indicatorlibrary. hqontario.ca/Indicator/Detailed/Caesarean-section-deliveries-low-and-very -low-risk-group/EN\# (accessed 2020 Dec. 2).

30. Murphy M, Fell D, Sprague A, et al. Data resource profile: Better Outcomes Registry \& Network (BORN) Ontario. Int J Epidemiol. In press.

31. Dunn S, Lanes A, Sprague AE, et al. Data accuracy in the Ontario Birth Registry: a chart re-abstraction study. BMC Health Serv Res 2019;19:1001.

32. Alsayegh E, Bos H, Campbell K, et al. No. 361: Caesarean delivery on maternal request. J Obstet Gynaecol Can 2018;40:967-71.

33. Hutcheon JA, Lee L, Joseph KS, et al. Feasibility of implementing a standardized clinical performance indicator to evaluate the quality of obstetrical care in British Columbia. Matern Child Health J 2015;19:2688-97. 
34. Mann S, Pratt S, Gluck P, et al. Assessing quality in obstetrical care:development of standardized measures. Jt Comm J Qual Patient Saf 2006;32:497-505.

35. Hutcheon JA, Lee L, Joseph KS, et al. Feasibility of implementing a standardized clinical performance indicator to evaluate the quality of obstetrical care in British Columbia. Matern Child Health J 2015;19:2688-97.

36. Standardized maternal and newborn levels of care definitions. Toronto: Provincial Council for Maternal and Child Health (PCMCH); 2013. Available: www. pcmch.on.ca/wp-content/uploads/2015/07/Level-of-Care-Guidelines-2011 -Updated-August1-20131.pdf (accessed 2020 Mar. 23).

37. Zou G. A modified poisson regression approach to prospective studies with binary data. Am J Epidemiol 2004;159:702-6.

38. Liu X, Landon MB, Cheng W, et al. Cesarean delivery on maternal request in China: What are the risks and benefits? Am J Obstet Gynecol 2015;212:817.e1-9.

39. Lavender T, Kingdon C, Hart A, et al. Could a randomised trial answer the controversy relating to elective caesarean section? National survey of consultant obstetricians and heads of midwifery. BMJ 2005;331:490-1.

40. Lavender T, Kingdon C. Primigravid women's views of being approached to participate in a hypothetical term cephalic trial of planned vaginal birth versus planned cesarean birth. Birth 2009;36:213-9.

41. Kottmel A, Hoesli I, Traub R, et al. Maternal request: A reason for rising rates of cesarean section? Arch Gynecol Obstet 2012;286:93-8.

42. Betrán AP, Ye J, Moller A-B, et al. The increasing trend in caesarean section rates: Global, regional and national estimates: 1990-2014. PLoS One 2016;11:e0148343.

43. What Mothers Say: The Canadian Maternity Experiences Survey. Ottawa: Public Health Agency of Canada; 2009. Available: www.publichealth.gc.ca/ mes (accessed 2019 Nov. 27).

44. Zhang J, Liu Y, Meikle S, et al. Cesarean delivery on maternal request in southeast China. Obstet Gynecol 2008;111:1077-82.

45. Boerma T, Ronsmans C, Melesse DY, et al. Global epidemiology of use of and disparities in caesarean sections. Lancet 2018;392:1341-8.
46. Cesar JA, Sauer JP, Carlotto K, et al. Cesarean section on demand: a population-based study in Southern Brazil. Rev Bras Saúde Mater Infant 2017;17. doi: 10.1590/1806-93042017000100006

47. Dursun $\mathrm{P}$, Yanik FB, Zeyneloglu HB, et al. Why women request cesarean section without medical indication? J Matern Fetal Neonatal Med 2011;24:1133-7.

48. Bergholt T, Østberg B, Legarth J, et al. Danish obstetricians' personal preference and general attitude to elective cesarean section on maternal request: a nation-wide postal survey. Acta Obstet Gynecol Scand 2004;83:262-6.

49. Atallah F, Bernstein PS, Acosta D, et al. The Adverse Outcome Index: putting quality into an outcome measure. Obstet Gynecol 2018;132:750-3.

50. Foglia LM, Nielsen PE, Hemann EA, et al. Accuracy of the Adverse Outcome Index: an obstetrical quality measure. Jt Comm J Qual Patient Saf 2015;41:370-7.

51. Liu X, Zhang J, Liu Y, et al. The association between cesarean delivery on maternal request and method of newborn feeding in China. PLoS One 2012; 7:e37336.

52. Hobbs AJ, Mannion CA, McDonald SW, et al. The impact of caesarean section on breastfeeding initiation, duration and difficulties in the first four months postpartum. BMC Pregnancy Childbirth 2016;16:90.

53. Prior E, Santhakumaran S, Gale C, et al. Breastfeeding after cesarean deliv ery: a systematic review and meta-analysis of world literature. Am J Clin Nutr 2012;95:1113-35.

54. Zanardo V, Svegliado G, Cavallin F, et al. Elective cesarean delivery: Does it have a negative effect on breastfeeding? Birth 2010;37:275-9.

55. Tickell KD, Lokken EM, Schaafsma TT, et al. Lower respiratory tract disorde hospitalizations among children born via elective early-term delivery. J Matern Fetal Neonatal Med 2016;29:1871-6.

56. Huang L, Chen $\mathrm{Q}$, Zhao $\mathrm{Y}$, et al. Is elective cesarean section associated with a higher risk of asthma? A meta-analysis. J Asthma 2015;52:16-25.

57. Chu S, Zhang Y, Jiang Y, et al. Cesarean section without medical indication and risks of childhood allergic disorder, attenuated by breastfeeding. Sci Rep 2017;7:9762.

\section{Competing interests: None declared.}

This article has been peer reviewed.

Affiliation: Better Outcomes Registry \& Network Ontario (Guo, Erwin, Corsi, Walker); OMNI Research Group (Guo, Murphy, Erwin, Fakhraei, Corsi, White, Harvey, Walker, Wen, El-Chaâr), Clinical Epidemiology Program, Ottawa Hospital Research Institute; Children's Hospital of Eastern Ontario Research Institute (Guo, Fakhraei, Corsi); Department of Obstetrics, Gynecology and Newborn Care (White, Wen, Walker, El-Chaâr), The Ottawa Hospital, Ottawa, Ont.; Department of Obstetrics and Gynecology (Gaudet), Kingston Health Sciences Centre; Department of Obstetrics and Gynecology (Gaudet), Queen's University, Kingston, Ont.

Contributors: Yanfang Guo, Daniel Corsi, Mark Walker, Shi Wen and Darine El-Chaâr conceived and designed the study. Yanfang Guo, Malia Murphy, Erica Erwin, Romina
Fakhraei and Darine El-Chaâr contributed to data acquisition, analysis and interpretation. Yanfang Guo and Malia Murphy drafted the manuscript. All of the authors revised the manuscript critically for important intellectual content, gave final approval of the version to be published and agreed to be accountable for all aspects of the work.

Content licence: This is an Open Access article distributed in accordance with the terms of the Creative Commons Attribution (CC BY-NC-ND 4.0) licence, which permits use, distribution and reproduction in any medium, provided that the original publication is properly cited, the use is noncommercial (i.e., research or educational use), and no modifications or adaptations are made. See: https://creativecommons.org/ licenses/by-nc-nd/4.0/

Funding: This study was supported by a Canadian Institutes of Health Research Foundation Grant (FDN 148438).
Data sharing: Data sharing regulations prevent these data from being made available publicly due to the personal health information in the datasets. Enquiries regarding BORN data must be directed to BORN Ontario (Science@BORNOntario.ca).

Disclaimer: This study was supported by a Canadian Institutes of Health Research Foundation Grant. The funding agency was not involved in study design, analysis or interpretation of data. The agency was not involved writing of this manuscript or in the decision to submit the article for publication. The data analyzed for this study are held securely at the prescribed registry, BORN Ontario.

Accepted: Mar. 8, 2021

Correspondence to: Darine El-Chaâr, delchaar@toh.ca 